\title{
Multiplex serum biomarker assessments: technical and biostatistical issues
}

Lisa H Butterfield ${ }^{1,2,3,4,5^{*}}$, Douglas M Potter ${ }^{1,2,6}$ and John M Kirkwood ${ }^{1,2,3+}$

\begin{abstract}
Background: Identification of predictive and prognostic biomarkers for patients with disease and undergoing different therapeutic options is a very active area of investigation. Many of these studies seek biomarkers among circulating proteins accessed in blood. Many levels of standardization in materials and procedures have been identified which can impact the resulting data.

Methods: Here, we have observed unexpected variability in levels of commonly tested analytes in serum which were processed and stored under standardized conditions. We have identified apparent changes in cytokine, chemokine and growth factor levels detected by multiplex Luminex assay in melanoma patient and healthy donor serum samples, over storage time at $-80^{\circ} \mathrm{C}$. Controls included Luminex kit standards, multiplexed cytokine standards and WHO cytokine controls. Data were analyzed by Wilcoxon rank-sum testing and Spearman's test for correlations.
\end{abstract}

Results: The interpretation of these changes is confounded by lot-to-lot kit standard curve reagent changes made by a single manufacturer of Luminex kits.

Conclusions: This study identifies previously unknown sources of variation in a commonly used biomarker assay, and suggests additional levels of controls needed for identification of true changes in circulating protein levels.

Keywords: serum, biomarkers, melanoma, cytokine, Luminex

\section{Background}

To improve the clinical efficacy of immunotherapies and our ability to stratify patients rationally for therapeutic intervention, biomarkers are critical to progress. The FDA's Critical Path prioritizes development of biomarkers, including a focus on aspects of: Biospecimens, Analytical Performance, Standardization and Harmonization and Bioinformatics. Accurate biomarkers offer the prospect for earlier diagnosis, improved precision of application of expensive and toxic therapies on the optimal patient populations, monitoring disease progression and therapeutic benefits as well as accelerating drug development and discovery. Guidelines for incorporation of biomarker studies in early clinical trials of novel agents have been published [1].

There is a critical need for development and validation of biomarkers to identify patients who can benefit from

\footnotetext{
* Correspondence: butterfieldl@upmc.edu

† Contributed equally

'University of Pittsburgh Cancer Institute, 5117 Centre Avenue, suite 1.27,

Pittsburgh, PA 15213, USA

Full list of author information is available at the end of the article
}

a particular form of immunotherapy. Only a fraction of patients benefit from IFN- $\alpha$ treatment [2], only a fraction of patients can achieve durable regressions in response to antigen vaccination [3], or antibody therapies, and we do not yet know the mechanisms responsible for therapeutic benefit. Despite substantial efforts from many groups, we do not know which parameters of immune response (and which assays used to assess these parameters) yield optimal results for efficacy analysis [4-7]. A major reason for this has been that objective clinical response rates are often below $10 \%$, confounding the measurement of significant correlations between biomarkers and clinical responses in studies of modest size. Another important issue is that assay results may depend on biological specimen handling before assessment, and on methodological differences in complex, high throughput assays.

A number of studies in melanoma have identified candidate biomarkers of response to therapy. These range from circulating cytokines and growth factors $[8,9]$, gene expression profiles in tumors [10], circulating tumor 
cells [11], serum autoantibody profiling [12] and tumor specific $\mathrm{T}$ cell IFN- $\gamma$ production [13] to molecular signaling pathways in tumors [14] and the nature of tumor infiltrating cells [15]. The vast majority of candidate biomarkers have not yet achieved routine clinical use due to lack of reproducibility, need for new technology and equipment, need for high quality tumor samples or high cost. The relative ease of collecting, processing, storing and shipping blood has made it a common resource for biomarker testing.

Several reports have identified phenotypic and functional changes in blood cells and serum components when the blood is held for hours or days and at different temperatures before processing [16-18]. These timedependent and temperature-dependent effects should be controlled for to the extent possible before blood processing. Standardized processing procedures by trained and competency-tested personnel can also improve immunologic assay data consistency [19]. In addition, use of freezers for sample storage that are monitored for temperature stability and that have 24 hours-a-day alarm response eliminates concerns that samples might undergo freeze-thaw cycles or be otherwise compromised by temperature changes during storage. Many of these central laboratory procedures for processing, storage and equipment maintenance are mandated by accreditation groups such as CLIA and FACT, and are described in resources from CLSI [20-22].

During an investigation of biomarkers of prolonged survival after IFN- $\alpha$ treatment in banked melanoma patient serum samples, we discovered a number of both technical and biostatistical analysis issues [23]. Our preliminary results identified a large number of serum cytokines that appeared to correlate significantly with survival. However, further dissection of the data revealed a number of technical issues that made interpretation of the data impossible.

Here, we have performed a time course analysis of cytokines, chemokines and growth factors measured in the banked serum of healthy donors and melanoma patients stored for various intervals, and analyzed by multiplex Luminex assay. We find that a number of these analytes appear to be unstable during storage. We have also tested several aspects of the Luminex assay performance and identified a number of concerns with these multiplexed assays. Biostatistical tests indicate that despite several layers of procedural standardization and levels of controls, reliable multiplexed cytokine and chemokine determinations may be compromised by length of time in storage and/or by the changes regularly made by assay kit manufacturers to different lots and the analyte standards included. These results raise concerns about serum biomarker studies and suggest that additional controls may be required to confidently compare levels over time and between lots of reagents from the same manufacturer.

\section{Methods \\ Study subjects}

All serum samples were obtained after written informed consent, and under IRB approved protocols of investigation at the University of Pittsburgh. The samples received in 2005 were obtained from 23 patients at two clinical sites (Pennsylvania and Indiana). The UPCI \#96099 banking protocol was utilized for the five 2010 melanoma patient sera tested. The UPCI \#04-001 healthy donor blood collection protocol was used for the blood obtained from 10 healthy donors in 2010.

\section{Blood processing and banking}

For serum collection, red top vaccutainer tubes (no anticoagulant) provided by our laboratory (Becton Dickinson \#6430) in kits were used. Upon arrival in the lab, the samples are checked for proper identification, given accession numbers, and either processed immediately or (if received after $4 \mathrm{pm}$ ) put in the refrigerator $\left(\right.$ at $4^{\circ} \mathrm{C}$ ) for processing the next morning. All samples were processed within 24 hours, including those drawn at external sites and shipped at ambient temperature overnight in insulated shipping containers. All processing was performed by technologists who received the same training, and the laboratory SOP \#0108 was followed. Technologists also undergo annual competency training. Samples were centrifuged for $10 \mathrm{~min}$ at $2,500 \mathrm{rpm}$ in a refrigerated centrifuge at $4^{\circ} \mathrm{C}$, then the serum was aliquoted into polypropylene freezer vials at $1.1 \mathrm{~mL}$ per vial and immediately placed in a $-80^{\circ} \mathrm{C}$ freezer. All samples were stored in a monitored freezer until testing, freezer temperatures did not fluctuate above $-55^{\circ} \mathrm{C}$ (during brief periods of high use). Samples were thawed before testing and repeated testing was performed on separate aliquots to eliminate variability from freeze-thaw cycles. The laboratory is certified under the Pennsylvania Department of Health, College of American Pathologists (CAP) and Clinical Laboratory Improvement Amendments (CLIA for Histocompatibility and General Immunology). The laboratory is registered with the FDA, and maintains a facilities master file (BB-MF-12244). The exploratory Luminex assay reported here is not used for clinical decision making, and is not a CLIA-certified assay.

\section{Luminex assay and controls}

The Luminex kits were obtained from the same manufacturer, which changed ownership during the period of the study (BioSource, Invitrogen, Life Technologies). Assays were performed only on serum samples that had been stored at $-80^{\circ} \mathrm{C}$. Serum samples were thawed in a 
refrigerator overnight (healthy donor controls, $<12$ hours total time) or at room temperature the day of the assay (patient samples), clarified in a microfuge for 10 min at $1,000 \mathrm{~g}$, then diluted with the assay diluent provided per assay manufacturer's instructions. Healthy donor and control samples were run in duplicate, but large numbers of patient sera were run in singlets. The same trained technologist performed all of the assays reported herein, according to the same laboratory SOP $\# 0037)$. The software used for all assays was the BioPlex System BioPlex Manager 4.0, which uses 5-parameter logistic regression. Each sample acquired $\geq 100$ bead events, per manufacturers' instructions. Analytical sensitivity was calculated based on two standard deviations from the background MFI of the standard curve. There were no changes in the antibodies used for the analytes of interest reported here, and the standards were benchmarked in the same way over the time period tested here. R\&D QC controls (R\&D Systems QC02) are reconstituted with assay diluent from the $\mathrm{Hu}$ Extracellular buffer kit LHB0001 (BioSource). Each lot provides expected values for several commonly tested cytokines (as measured by R\&D Systems ELISA assays). Additional kit details are presented in Additional File 1, Table S1.

To address potential inter-analysis variability, 770 data points from 2005 and 430 data points from 2010 were re-analyzed at the same time (2011) with version 6.0 software, on the original machine. There were $0 / 1,200$ changes in the resulting absolute values obtained.

\section{WHO cytokine standards}

WHO cytokine standards were resuspended as follows: 117187 GM-CSF WHO 88/646 10, 000 IU: contents of the ampoule were dissolved with $0.5 \mathrm{~mL}$ sterile distilled water and brought up to $1 \mathrm{~mL}$ with PBS. Further 1:10 dilution was performed with AIM V (Invitrogen) medium. 117173 IL-4 WHO 88/656 $0.1 \mu \mathrm{g}=1,000$ arbitrary units per ampoule: contents of the ampule were resuspended with $\mathrm{PBS} / 1 \% \mathrm{BSA}$, and the 1:10 dilution was performed with AIM V. 117184 IL-10 WHO 92/516 1 $\mu \mathrm{g}=5,000 \mathrm{RU}$ per ampoule: contents of the ampoule were dissolved with $0.5 \mathrm{~mL}$ sterile distilled water and then brought up to $1 \mathrm{~mL}$ with PBS. Further 1:10 dilution was performed with AIM V. 117177 IL-8 WHO 89/ $5201 \mu \mathrm{g}=1$, $000 \mathrm{RU}$ per ampoule $=1,000,000 \mathrm{pg} / \mathrm{mL}$ : contents of the ampoule were resuspended with $\mathrm{PBS} / 1 \%$ BSA and the 1:10 dilution was performed with AIM V. To assay the WHO standards, each was diluted 1:10 (20 $\mu \mathrm{L}$ WHO standard dilution (above) $+180 \mu \mathrm{L}$ assay diluent) and 1:50 (10 $\mu \mathrm{L} \mathrm{WHO}+490 \mu \mathrm{L}$ assay diluent $)$. The dilutions were treated as samples in the assay, such that the final dilutions were $1: 20$ and $1: 100$, relative to the Luminex kit standard curve (the assayed well contains $50 \mu \mathrm{L}$ of the dilution $+50 \mu \mathrm{L}$ of assay diluent).

\section{Biostatistical Methods}

Analyte concentrations were compared at two time points with a one-sample Wilcoxon rank-sum test on the ratio of the two concentrations. Correlation was assessed with Spearman's test. All p-values are twosided. Assay results below the lower limit of detection or above the upper limit of quantitation were not used in the analysis.

\section{Results and Discussion}

During the analysis of a retrospective biomarker study conducted with a set of banked sera from melanoma patients [23], we discovered a potential correlation between the levels of analytes measured by Luminex and the time that the sera were stored at $-80^{\circ} \mathrm{C}$. Therefore, we examined several aspects of serum storage and the Luminex assay.

\section{Repeat testing in $\mathbf{2 0 1 0}$ of sera stored in $\mathbf{2 0 0 5}$}

Our first sample set consisted of 23 melanoma patient sera (the "old patients") who had a blood sample drawn in 2005, and had a Luminex assay performed on serum samples, on either $10 / 31 / 2005,11 / 01 / 2005$ or $2 / 17 / 2006$; we refer to these as the "early" assays. To determine any changes over storage time, we thawed aliquots (not previously thawed) and tested a subset of the analytes originally tested, again by Luminex (Table 1). Unexpectedly, we identified a number of apparent changes in analyte levels. We repeated these measurements up to three times (depending on the number of previously untouched aliquots remaining) for these 23 samples: (2/02/10, 5/13/ 2010 and 8/11/2010)-the "late" assays. Seven of the 10 analytes we examined had highly significant changes during the approximately 5 years of storage at $-80^{\circ} \mathrm{C}$.

There were different patterns seen for different groups of analytes, some of which were relatively stable over time (IL-4, change over time: $\mathrm{p}=0.28$ ) while others were found to change (IL-10, $\mathrm{p}=0.093$; GM-CSF, $\mathrm{p}=0.11$ ). Levels of some of the analytes decreased over the storage time (IL-6, p = 0.00021; decreasing in 21/23 samples; TNF $\alpha, p=0.0078$, decreasing in 20/23). Surprisingly, the IL-8 levels were significantly increased from the initial test to the subsequent tests 5 years later (IL-8, p = 0.000030 , approximately 5 -fold increased in $23 / 23$ patient samples). MCP-1 levels also increased in a majority of samples (MCP-1, p = 0.00012) (Table 1/Figure 1). Each p-value was computed with a one-sample Wilcoxon test on the ratio of the $5 / 13 / 2010$ assay result (for which we had the most data) to the result of the early assay.

\section{Healthy donor and melanoma patient serum time course in $\mathbf{2 0 1 0}$}

To determine whether we could detect similar changes over a period of months, we drew blood from 10 healthy 
Table 1 Old patient Serum Samples

\begin{tabular}{|c|c|c|c|c|c|c|c|c|c|c|c|c|c|}
\hline Sample & $\begin{array}{c}\text { Date } \\
\text { Drawn }\end{array}$ & $\begin{array}{l}\text { Draw } \\
\text { Date }\end{array}$ & $\begin{array}{c}\text { Assay } \\
\text { Date }\end{array}$ & $\begin{array}{c}\mathrm{IL}-4 \\
\mathrm{pg} / \mathrm{mL}\end{array}$ & $\begin{array}{c}\text { IL-6 } \\
\mathrm{pg} / \mathrm{mL}\end{array}$ & $\begin{array}{c}\mathrm{IL}-8 \\
\mathrm{pg} / \mathrm{mL}\end{array}$ & $\begin{array}{c}\mathrm{IL}-10 \\
\mathrm{pg} / \mathrm{mL}\end{array}$ & $\begin{array}{l}\text { TNF- } \alpha \\
\mathrm{pg} / \mathrm{mL}\end{array}$ & $\begin{array}{l}\text { IFN-g } \\
\mathrm{pg} / \mathrm{mL}\end{array}$ & $\begin{array}{c}\text { GM-CSF } \\
\mathrm{pg} / \mathrm{mL}\end{array}$ & $\begin{array}{l}\mathrm{IP}-10 \\
\mathrm{pg} / \mathrm{mL}\end{array}$ & $\begin{array}{c}\mathrm{MIG} \\
\mathrm{pg} / \mathrm{mL}\end{array}$ & $\begin{array}{l}\mathrm{MCP}-1 \\
\mathrm{pg} / \mathrm{mL}\end{array}$ \\
\hline \multirow[t]{3}{*}{ patient 1} & $6 / 2 / 2005$ & $6 / 1 / 2005$ & $10 / 31 / 2005$ & $<5$ & 217 & 64 & $<10$ & 38 & 29 & $<15$ & 1339 & 62 & 10145 \\
\hline & & & 8/11/2010 & 25 & 106 & 353 & 6 & $<10$ & 28 & $<15$ & 1214 & 48 & $>7200$ \\
\hline & & & $8 / 11 / 2010$ & 16 & 98 & 370 & 6 & $<10$ & 29 & $<15$ & 1195 & 42 & $>7200$ \\
\hline \multirow[t]{3}{*}{ patient 2} & $6 / 2 / 2005$ & $6 / 1 / 2005$ & $10 / 31 / 2005$ & $<5$ & 41 & 24 & $<10$ & 19 & 23 & $<15$ & $>2800$ & 130 & 2725 \\
\hline & & & 8/11/2010 & 13 & 20 & 132 & 7 & $<10$ & 24 & $<15$ & $>9600$ & 164 & 3149 \\
\hline & & & $8 / 11 / 2010$ & 13 & 22 & 144 & 7 & $<10$ & 26 & $<15$ & $>9600$ & 162 & 2989 \\
\hline \multirow[t]{3}{*}{ patient 3} & $6 / 2 / 2005$ & $6 / 1 / 2005$ & $10 / 31 / 2005$ & $<5$ & 13 & 23 & $<10$ & 7 & $<14$ & $<15$ & 55 & 62 & 384 \\
\hline & & & $8 / 11 / 2010$ & 5 & 5 & 125 & 5 & $<10$ & $<5$ & $<15$ & 83 & 90 & 419 \\
\hline & & & $8 / 11 / 2010$ & 7 & 6 & 151 & 5 & $<10$ & $<5$ & $<15$ & 83 & 98 & 455 \\
\hline \multirow[t]{6}{*}{ patient 4} & $7 / 30 / 2005$ & $7 / 30 / 2005$ & $11 / 1 / 2005$ & 32 & 49 & 17 & 17 & 83 & 95 & 173 & 64 & 241 & 394 \\
\hline & & & 2/2/2010 & 47 & 17 & 75 & 20 & 21 & 63 & 132 & 87 & 209 & 633 \\
\hline & & & $5 / 13 / 2010$ & 42 & 14 & 73 & 20 & 20 & 51 & 124 & 84 & 153 & 554 \\
\hline & & & $5 / 13 / 2010$ & 42 & 15 & 69 & 22 & 21 & 62 & 133 & 84 & 154 & 518 \\
\hline & & & $8 / 11 / 2010$ & 55 & 21 & 89 & 27 & 28 & 118 & 89 & 90 & 213 & 140 \\
\hline & & & $8 / 11 / 2010$ & 47 & 23 & 87 & 33 & 32 & 144 & 105 & 90 & 209 & 128 \\
\hline \multirow[t]{4}{*}{ patient 5} & 8/9/2005 & 8/9/2005 & $11 / 1 / 2005$ & 12 & 2199 & 266 & 43 & 100 & 178 & $<15$ & $>2800$ & 407 & $>17800$ \\
\hline & & & 2/2/2010 & 6 & 1105 & 1469 & $<14$ & 17 & 159 & 37 & 2178 & 374 & 11991 \\
\hline & & & $5 / 13 / 2010$ & 13 & 949 & 1494 & $<14$ & 16 & 140 & 36 & 2476 & 313 & 10275 \\
\hline & & & $5 / 13 / 2010$ & 12 & 971 & 1428 & $<14$ & 13 & 121 & 24 & 2233 & 300 & 9045 \\
\hline \multirow[t]{4}{*}{ patient 6} & $8 / 9 / 2005$ & 8/9/2005 & $11 / 1 / 2005$ & 14 & 592 & 171 & 28 & 52 & 229 & $<15$ & $>2800$ & 2586 & 10705 \\
\hline & & & 2/2/2010 & 10 & 350 & 1016 & $<14$ & $<10$ & 198 & 37 & 2176 & 2039 & 11703 \\
\hline & & & $5 / 13 / 2010$ & 13 & 275 & 971 & $<14$ & $<10$ & 155 & 18 & $>2980$ & 2276 & 9492 \\
\hline & & & $5 / 13 / 2010$ & $<5$ & 270 & 968 & $<14$ & $<10$ & 160 & 11 & $>2980$ & 2294 & 10581 \\
\hline \multirow[t]{3}{*}{ patient 7} & $8 / 15 / 2005$ & $8 / 15 / 2005$ & $11 / 1 / 2005$ & $<5$ & 19 & 47 & $<5$ & 13 & $<14$ & $<15$ & 285 & 40 & 2565 \\
\hline & & & $5 / 13 / 2010$ & 8 & 24 & 242 & $<14$ & $<10$ & 31 & $<15$ & 445 & 25 & 5453 \\
\hline & & & $5 / 13 / 2010$ & $<5$ & 20 & 234 & $<14$ & $<10$ & 27 & $<15$ & 360 & 25 & 5088 \\
\hline \multirow[t]{6}{*}{ patient 8} & $8 / 20 / 2005$ & $8 / 20 / 2005$ & $11 / 1 / 2005$ & 36 & 48 & 17 & 17 & 80 & 111 & 197 & 27 & 182 & 379 \\
\hline & & & 2/2/2010 & 46 & 17 & 99 & 23 & 23 & 78 & 146 & 45 & 172 & 614 \\
\hline & & & $5 / 13 / 2010$ & 48 & 16 & 87 & 26 & 25 & 84 & 175 & 40 & 128 & 550 \\
\hline & & & $5 / 13 / 2010$ & 50 & 15 & 84 & 22 & 21 & 70 & 151 & 41 & 117 & 544 \\
\hline & & & $8 / 11 / 2010$ & 33 & 15 & 89 & 23 & 21 & 103 & 85 & 47 & 136 & 119 \\
\hline & & & $8 / 11 / 2010$ & 49 & 21 & 107 & 29 & 30 & 136 & 95 & 48 & 150 & 125 \\
\hline \multirow[t]{3}{*}{ patient 9} & $9 / 15 / 2005$ & $9 / 15 / 2005$ & $11 / 1 / 2005$ & 42 & 67 & 21 & 11 & 72 & 122 & 208 & 275 & 383 & 1119 \\
\hline & & & $5 / 13 / 2010$ & 77 & 22 & 78 & 28 & 36 & 80 & 224 & 346 & 328 & 2162 \\
\hline & & & $5 / 13 / 2010$ & 80 & 22 & 76 & 27 & 34 & 87 & 233 & 347 & 306 & 2270 \\
\hline \multirow[t]{3}{*}{ patient 10} & 9/19/2005 & 9/19/2005 & $2 / 17 / 2006$ & $<5$ & 19 & 45 & $<5$ & 13 & $<7$ & $<15$ & 183 & 42 & 1656 \\
\hline & & & $5 / 13 / 2010$ & 8 & 24 & 287 & $<14$ & $<10$ & 26 & $<15$ & 350 & 21 & 5509 \\
\hline & & & $5 / 13 / 2010$ & 8 & 22 & 290 & $<14$ & $<10$ & 29 & $<15$ & 347 & 17 & 5021 \\
\hline \multirow[t]{3}{*}{ patient 11} & $9 / 16 / 2005$ & $9 / 22 / 2005$ & $11 / 1 / 2005$ & 48 & 94 & 2675 & 24 & 142 & 135 & 201 & 902 & 419 & 10026 \\
\hline & & & $5 / 13 / 2010$ & 85 & 37 & 12663 & 29 & 39 & 114 & 272 & 988 & 300 & 13807 \\
\hline & & & $5 / 13 / 2010$ & 77 & 37 & 13690 & 27 & 34 & 114 & 266 & 1337 & 285 & 14377 \\
\hline
\end{tabular}


Table 1 Old patient Serum Samples (Continued)

\begin{tabular}{|c|c|c|c|c|c|c|c|c|c|c|c|c|c|}
\hline & & & $8 / 11 / 2010$ & 93 & 41 & 14814 & 26 & 59 & 72 & 219 & 716 & 340 & $>7200$ \\
\hline & & & $8 / 11 / 2010$ & 110 & 48 & 12823 & 30 & 58 & 80 & 238 & 793 & 364 & $>7200$ \\
\hline \multirow[t]{4}{*}{ patient 12} & 9/28/2005 & $9 / 28 / 2005$ & 2/17/2006 & 62 & 92 & 27 & 39 & 82 & 183 & 328 & 51 & 270 & 436 \\
\hline & & & $2 / 2 / 2010$ & 46 & 22 & 92 & 36 & 20 & 118 & 222 & 88 & 200 & 909 \\
\hline & & & $5 / 13 / 2010$ & 43 & 18 & 75 & 35 & 20 & 109 & 221 & 76 & 125 & 741 \\
\hline & & & $5 / 13 / 2010$ & 34 & 18 & 88 & 35 & 22 & 124 & 208 & 78 & 165 & 755 \\
\hline \multirow[t]{3}{*}{ patient 13} & $10 / 6 / 2005$ & $10 / 5 / 2005$ & $11 / 1 / 2005$ & 28 & 67 & 51 & 8 & 80 & 77 & 131 & 877 & 326 & 6818 \\
\hline & & & $8 / 11 / 2010$ & 83 & 42 & 342 & 29 & 55 & 64 & 225 & 725 & 332 & $>7200$ \\
\hline & & & $8 / 11 / 2010$ & 116 & 44 & 335 & 33 & 72 & 79 & 228 & 802 & 356 & 7345 \\
\hline \multirow[t]{3}{*}{ patient 14} & $10 / 7 / 2005$ & $10 / 6 / 2005$ & $11 / 1 / 2005$ & 42 & 67 & 24 & 18 & 66 & 122 & 156 & 353 & 711 & 1266 \\
\hline & & & $8 / 11 / 2010$ & 89 & 39 & 118 & 35 & 66 & 59 & 237 & 314 & 906 & 1088 \\
\hline & & & $8 / 11 / 2010$ & 70 & 35 & 114 & 30 & 53 & 52 & 189 & 328 & 891 & 1057 \\
\hline \multirow[t]{4}{*}{ patient 15} & $10 / 12 / 2005$ & - & $2 / 17 / 2006$ & 51 & 76 & 26 & 32 & 86 & 180 & 276 & 63 & 257 & 395 \\
\hline & & & $2 / 2 / 2010$ & 38 & 21 & 113 & 48 & 23 & 146 & 255 & 107 & 245 & 801 \\
\hline & & & $5 / 13 / 2010$ & 35 & 17 & 95 & 44 & 23 & 116 & 205 & 89 & 170 & 601 \\
\hline & & & $5 / 13 / 2010$ & 28 & 15 & 100 & 42 & 20 & 107 & 224 & 82 & 168 & 576 \\
\hline \multirow[t]{5}{*}{ patient 16} & 10/17/2005 & - & $2 / 17 / 2006$ & $<5$ & 54 & 60 & $<5$ & 34 & $<7$ & $<15$ & 434 & 55 & 3950 \\
\hline & & & $5 / 13 / 2010$ & 5 & 41 & 368 & $<14$ & $<10$ & 39 & $<15$ & 780 & 25 & 10159 \\
\hline & & & $5 / 13 / 2010$ & 11 & 43 & 373 & $<14$ & $<10$ & 39 & $<15$ & 846 & 23 & 10552 \\
\hline & & & $8 / 11 / 2010$ & 21 & 52 & 402 & 6 & $<10$ & 6 & 15 & 464 & 35 & 4616 \\
\hline & & & $8 / 11 / 2010$ & 8 & 29 & 391 & $<5$ & $<10$ & $<5$ & $<15$ & 465 & 35 & 4777 \\
\hline \multirow[t]{5}{*}{ patient 17} & $11 / 3 / 2005$ & $11 / 3 / 2005$ & $2 / 17 / 2006$ & 23 & 52 & 11 & $<5$ & 49 & 75 & 111 & 155 & 283 & 686 \\
\hline & & & $5 / 13 / 2010$ & 72 & 23 & 57 & 24 & 31 & 67 & 221 & 198 & 288 & 1734 \\
\hline & & & $5 / 13 / 2010$ & 17 & 9 & 27 & $<14$ & $<10$ & 14 & 53 & 186 & 218 & 1706 \\
\hline & & & $8 / 11 / 2010$ & 90 & 36 & 63 & 28 & 60 & 67 & 222 & 203 & 370 & 757 \\
\hline & & & $8 / 11 / 2010$ & 85 & 30 & 60 & 24 & 52 & 56 & 213 & 202 & 325 & 705 \\
\hline \multirow[t]{4}{*}{ patient 18} & $11 / 16 / 2005$ & - & $2 / 17 / 2006$ & 7 & 18 & 14 & $<5$ & 20 & 29 & 44 & 41 & 79 & 327 \\
\hline & & & $2 / 2 / 2010$ & 16 & 15 & 74 & $<14$ & $<10$ & 34 & 51 & 59 & 93 & 807 \\
\hline & & & $5 / 13 / 2010$ & 10 & 12 & 71 & $<14$ & $<10$ & 20 & 24 & 57 & 50 & 611 \\
\hline & & & $5 / 13 / 2010$ & 8 & 10 & 72 & $<14$ & $<10$ & 24 & 30 & 52 & 48 & 617 \\
\hline \multirow[t]{4}{*}{ patient 19} & $11 / 16 / 2005$ & - & 2/17/2006 & 10 & 48 & 18 & $<5$ & 41 & 39 & 67 & 144 & 96 & 1143 \\
\hline & & & 2/2/2010 & 16 & 30 & 116 & $<14$ & $<10$ & 43 & 75 & 248 & 108 & 2812 \\
\hline & & & $5 / 13 / 2010$ & 13 & 22 & 100 & $<14$ & 10 & 35 & 67 & 202 & 75 & 2101 \\
\hline & & & $5 / 13 / 2010$ & 11 & 24 & 108 & $<14$ & $<10$ & 38 & 61 & 220 & 67 & 2304 \\
\hline \multirow[t]{4}{*}{ patient 20} & $12 / 8 / 2005$ & $12 / 8 / 2005$ & $2 / 17 / 2006$ & 27 & 31 & 10 & $<5$ & 62 & 73 & 149 & 35 & 162 & 452 \\
\hline & & & $2 / 2 / 2010$ & 49 & 17 & 61 & 24 & 24 & 89 & 146 & 60 & 162 & 1422 \\
\hline & & & $5 / 13 / 2010$ & 43 & 12 & 48 & 19 & 24 & 70 & 137 & 52 & 108 & 1114 \\
\hline & & & $5 / 13 / 2010$ & 41 & 12 & 50 & 21 & 21 & 77 & 137 & 55 & 106 & 1234 \\
\hline \multirow[t]{5}{*}{ patient 21} & $12 / 12 / 2005$ & $12 / 9 / 2005$ & $2 / 17 / 2006$ & $<5$ & 24 & 41 & $<5$ & 16 & $<7$ & $<15$ & 537 & 35 & 1236 \\
\hline & & & $5 / 13 / 2010$ & 8 & 22 & 235 & $<14$ & $<10$ & 29 & $<15$ & 682 & 25 & 3153 \\
\hline & & & $5 / 13 / 2010$ & 10 & 23 & 233 & $<14$ & $<10$ & 27 & $<15$ & 789 & 25 & 3457 \\
\hline & & & $8 / 11 / 2010$ & 14 & 29 & 235 & 11 & $<10$ & 7 & $<15$ & 518 & 34 & 1423 \\
\hline & & & $8 / 11 / 2010$ & 13 & 25 & 238 & 11 & $<10$ & 6 & $<15$ & 546 & 39 & 1322 \\
\hline
\end{tabular}


Table 1 Old patient Serum Samples (Continued)

\begin{tabular}{|c|c|c|c|c|c|c|c|c|c|c|c|c|c|}
\hline \multirow[t]{3}{*}{ patient 22} & $1 / 26 / 2006$ & $1 / 25 / 2006$ & $2 / 17 / 2006$ & 8 & 30 & 4 & $<5$ & 24 & 24 & 40 & 706 & 216 & 24 \\
\hline & & & $8 / 11 / 2010$ & 47 & 22 & 44 & 17 & 45 & 37 & 196 & 332 & 283 & 888 \\
\hline & & & $8 / 11 / 2010$ & 56 & 26 & 47 & 19 & 53 & 42 & 223 & 318 & 283 & 959 \\
\hline \multirow[t]{4}{*}{ patient 23} & $1 / 26 / 2006$ & $1 / 25 / 2006$ & $2 / 17 / 2006$ & 8 & 56 & 68 & $<5$ & 75 & 20 & $<15$ & 8705 & 266 & 75 \\
\hline & & & $8 / 11 / 2010$ & 75 & 3953 & 534 & 19 & 56 & 50 & 202 & 650 & 339 & $>7200$ \\
\hline & & & $8 / 11 / 2010$ & 76 & 4542 & 525 & 19 & 58 & 48 & 210 & 695 & 318 & $>7200$ \\
\hline & & & & & 223 & & & & & & & & \\
\hline
\end{tabular}

donors (HD, Additional File 2, Table S2, Table 2 data) and 5 melanoma patients ("new patients") (Additional File 3, Table S3, Table 3 data). HD samples were tested initially 2 months after processing and freezing, and then twice more, at 5 and 8 months of storage on the same dates as the old patient sample described above. The melanoma patient samples were tested 2 days after processing and cryopreservation, and again 3 months later.

As expected, HD samples had low circulating levels of many analytes tested. These HD control samples also showed changes in analyte levels, even after short-term storage. Again, some analytes were stable, others were much less stable. IL- 8 increased in $3 / 10 \mathrm{HD}$, at the 8 month timepoint (n.s.), but not by 5 months. IP-10 also began to increase in $5 / 10 \mathrm{HD}$ at 8 months $(\mathrm{p}=0.01)$. Several analytes decreased in the relatively short storage time interval, including IFN $\gamma(\mathrm{p}=0.06$ at 5 mo., $\mathrm{p}=$ 0.03 at 8 mo., decreasing in 6/10 HD), and MCP-1, which showed the most dramatic decreases in $10 / 10$ donors, by 8 mo. $(p=0.002)$. These changes, between the first assay and the second and third assays (100 and 190 days apart), are shown graphically in Figure 2. The melanoma patient samples did not show significant changes within the short storage time, with the exception of MCP-1, which decreased in 5/5 samples within 3 months $(p=0.06)$. When the ratios of the concentrations of the different analytes measured at different

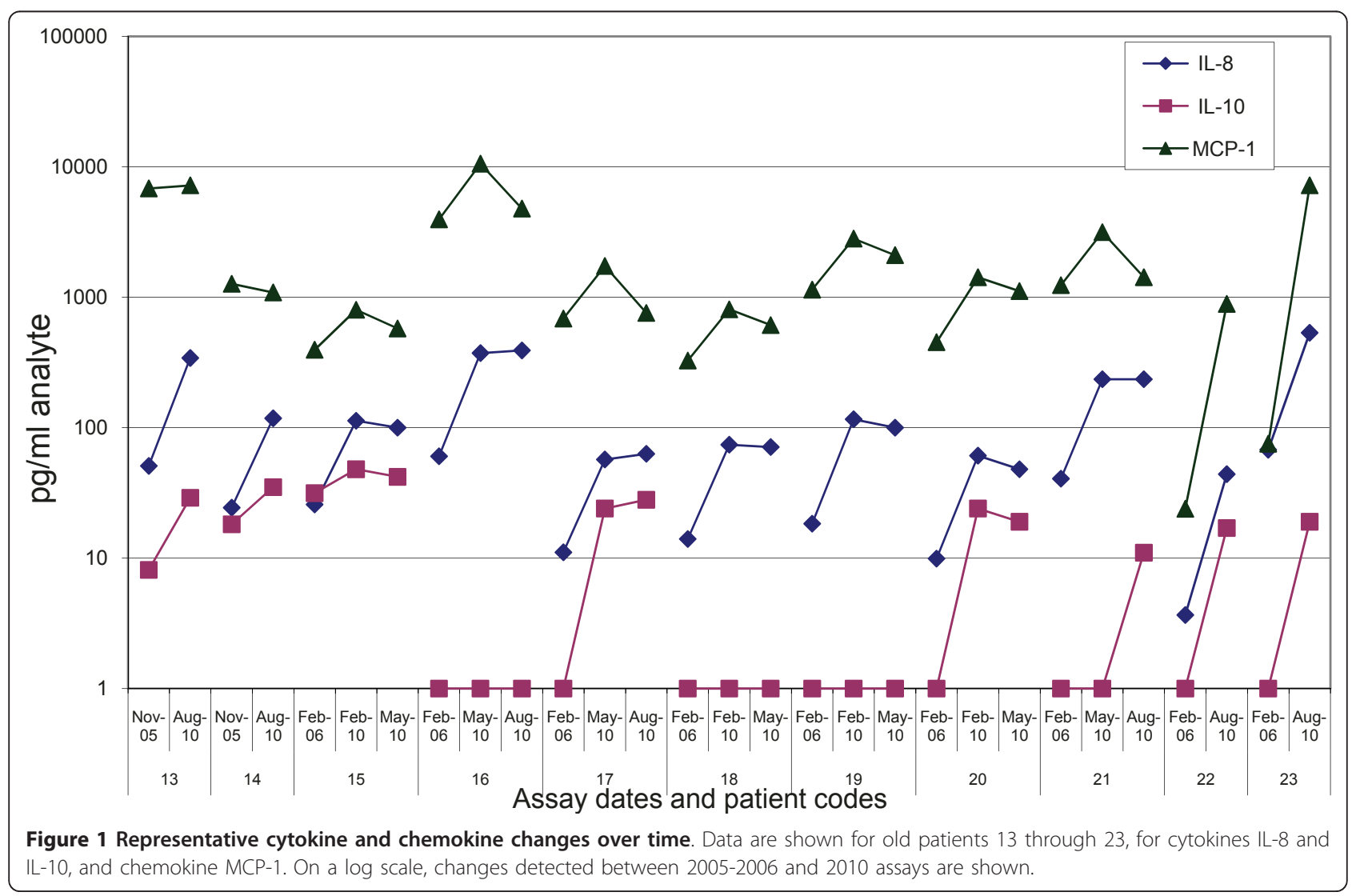


Table 2 Healthy Donor Sera Analysis

\begin{tabular}{|c|c|c|c|c|c|c|c|c|c|c|c|c|}
\hline Sample & $\begin{array}{l}\text { Date } \\
\text { Drawn }\end{array}$ & $\begin{array}{l}\text { Assay } \\
\text { Date }\end{array}$ & $\begin{array}{c}\mathrm{IL}-4 \\
\mathrm{pg} / \mathrm{mL}\end{array}$ & $\begin{array}{c}\text { IL-6 } \\
\mathrm{pg} / \mathrm{mL}\end{array}$ & $\begin{array}{c}\mathrm{IL}-8 \\
\mathrm{pg} / \mathrm{mL}\end{array}$ & $\begin{array}{c}\mathrm{IL}-10 \\
\mathrm{pg} / \mathrm{mL}\end{array}$ & $\begin{array}{l}\text { TNF- } \alpha \\
\mathrm{pg} / \mathrm{mL}\end{array}$ & $\begin{array}{l}\text { IFN-g } \\
\mathrm{pg} / \mathrm{mL}\end{array}$ & $\begin{array}{c}\mathrm{GM}-\mathrm{CSF} \\
\mathrm{pg} / \mathrm{mL}\end{array}$ & $\begin{array}{l}\mathrm{IP}-10 \\
\mathrm{pg} / \mathrm{mL}\end{array}$ & $\begin{array}{c}\mathrm{MIG} \\
\mathrm{pg} / \mathrm{mL}\end{array}$ & $\begin{array}{l}\mathrm{MCP}-1 \\
\mathrm{pg} / \mathrm{mL}\end{array}$ \\
\hline \multirow[t]{6}{*}{ Healthy donor 1} & $12 / 14 / 2009$ & $2 / 2 / 2010$ & 57 & 43 & 25 & 21 & 16 & 44 & 90 & 28 & 143 & 324 \\
\hline & & 2/2/2010 & 58 & 48 & 22 & 25 & 16 & 49 & 94 & 30 & 143 & 319 \\
\hline & & $5 / 13 / 2010$ & 50 & 39 & 19 & 22 & 13 & 31 & 87 & 25 & 103 & 263 \\
\hline & & $5 / 13 / 2010$ & 52 & 29 & 18 & 17 & 11 & 29 & 78 & 25 & 100 & 254 \\
\hline & & 8/11/2010 & 36 & 42 & 11 & 25 & $<10$ & 20 & 40 & 31 & 71 & 30 \\
\hline & & $8 / 11 / 2010$ & 29 & 39 & 11 & 20 & $<10$ & 16 & 39 & 29 & 64 & 31 \\
\hline \multirow[t]{6}{*}{ Healthy donor 2} & $12 / 16 / 2009$ & $2 / 2 / 2010$ & 57 & 61 & 44 & 41 & 20 & 160 & 179 & 31 & 96 & 632 \\
\hline & & 2/2/2010 & 59 & 59 & 40 & 42 & 18 & 163 & 151 & 31 & 105 & 589 \\
\hline & & $5 / 13 / 2010$ & 44 & 48 & 29 & 31 & 15 & 109 & 129 & 28 & 70 & 529 \\
\hline & & $5 / 13 / 2010$ & 41 & 49 & 34 & 33 & 15 & 109 & 128 & 27 & 69 & 521 \\
\hline & & $8 / 11 / 2010$ & 82 & 80 & 63 & 37 & 42 & 100 & 84 & 40 & 151 & 160 \\
\hline & & $8 / 11 / 2010$ & 67 & 91 & 68 & 39 & 34 & 105 & 81 & 35 & 165 & 138 \\
\hline \multirow[t]{6}{*}{ Healthy donor 3} & $12 / 17 / 2009$ & $2 / 2 / 2010$ & 17 & $<8$ & 18 & $<14$ & $<10$ & $<12$ & $<15$ & 23 & 20 & 977 \\
\hline & & $2 / 2 / 2010$ & 21 & $<8$ & 19 & $<14$ & $<10$ & $<12$ & $<15$ & 23 & 13 & 921 \\
\hline & & $5 / 13 / 2010$ & 22 & $<8$ & 21 & $<14$ & $<10$ & $<12$ & $<15$ & 22 & $<12$ & 803 \\
\hline & & $5 / 13 / 2010$ & 20 & $<8$ & 18 & $<14$ & $<10$ & $<12$ & $<15$ & 23 & $<12$ & 763 \\
\hline & & 8/11/2010 & 24 & $<3$ & 18 & $<5$ & $<10$ & $<5$ & $<15$ & 19 & 11 & 241 \\
\hline & & 8/11/2010 & 32 & $<3$ & 21 & $<5$ & $<10$ & $<5$ & $<15$ & 23 & 16 & 258 \\
\hline \multirow[t]{6}{*}{ Healthy donor 4} & $12 / 18 / 2009$ & $2 / 2 / 2010$ & 111 & 29 & 88 & 51 & 50 & 189 & 253 & 39 & 196 & 577 \\
\hline & & $2 / 2 / 2010$ & 121 & 31 & 90 & 51 & 56 & 212 & 262 & 37 & 216 & 579 \\
\hline & & $5 / 13 / 2010$ & 81 & 20 & 66 & 38 & 39 & 147 & 211 & 30 & 128 & 468 \\
\hline & & $5 / 13 / 2010$ & 76 & 21 & 60 & 36 & 33 & 142 & 201 & 30 & 133 & 440 \\
\hline & & $8 / 11 / 2010$ & 232 & 48 & 160 & 65 & 90 & 137 & 173 & 49 & 277 & 171 \\
\hline & & 8/11/2010 & 222 & 46 & 167 & 68 & 92 & 141 & 167 & 48 & 276 & 183 \\
\hline \multirow[t]{6}{*}{ Healthy donor 5} & $12 / 21 / 2009$ & $2 / 2 / 2010$ & 12 & 9 & 33 & $<14$ & $<10$ & 18 & 33 & 20 & 32 & 194 \\
\hline & & 2/2/2010 & $<5$ & $<8$ & 30 & $<14$ & $<10$ & 14 & 25 & 20 & 13 & 192 \\
\hline & & $5 / 13 / 2010$ & 5 & $<8$ & 34 & $<14$ & $<10$ & 14 & $<15$ & 19 & $<12$ & 177 \\
\hline & & $5 / 13 / 2010$ & $<5$ & $<8$ & 32 & $<14$ & $<10$ & $<12$ & $<15$ & 20 & 12 & 174 \\
\hline & & 8/11/2010 & 7 & 7 & 26 & 8 & $<10$ & $>5$ & $<15$ & 25 & 20 & 16 \\
\hline & & 8/11/2010 & 12 & 12 & 33 & 10 & $<10$ & $<5$ & 23 & 27 & 20 & 17 \\
\hline \multirow[t]{6}{*}{ Healthy donor 6} & $12 / 21 / 2009$ & $2 / 2 / 2010$ & 19 & 8 & 24 & $<14$ & $<10$ & $<12$ & 37 & 22 & 50 & 496 \\
\hline & & $2 / 2 / 2010$ & $<5$ & $<8$ & 28 & $<14$ & $<10$ & $<12$ & 17 & 22 & 37 & 558 \\
\hline & & $5 / 13 / 2010$ & 19 & $<8$ & 15 & $<14$ & $<10$ & $<12$ & 18 & 19 & 40 & 434 \\
\hline & & $5 / 13 / 2010$ & 10 & $<8$ & $<12$ & $<14$ & $<10$ & $<12$ & 18 & 18 & 36 & 413 \\
\hline & & 8/11/2010 & 12 & 12 & 47 & 12 & 14 & 7 & 21 & 27 & 48 & 111 \\
\hline & & 8/11/2010 & 18 & 11 & 45 & 13 & 13 & 7 & 21 & 28 & 51 & 108 \\
\hline \multirow[t]{6}{*}{ Healthy donor 7} & $12 / 22 / 2009$ & $2 / 2 / 2010$ & 16 & $<8$ & 38 & $<14$ & $<10$ & 35 & 56 & 19 & 66 & 1040 \\
\hline & & $2 / 2 / 2010$ & 17 & 9 & 40 & $<14$ & 10 & 35 & 62 & 19 & 66 & 1019 \\
\hline & & $5 / 13 / 2010$ & 19 & $<8$ & 35 & $<14$ & $<10$ & 40 & 51 & 17 & 50 & 843 \\
\hline & & $5 / 13 / 2010$ & 20 & $<8$ & 41 & $<14$ & $<10$ & 33 & 51 & 18 & 53 & 848 \\
\hline & & $8 / 11 / 2010$ & 13 & 6 & 28 & 28 & $<10$ & 19 & 37 & 21 & 24 & 245 \\
\hline & & $8 / 11 / 2010$ & 16 & 10 & 30 & 41 & 11 & 25 & 49 & 24 & 24 & 246 \\
\hline \multirow[t]{2}{*}{ Healthy donor 8} & $12 / 23 / 2009$ & $2 / 2 / 2010$ & 54 & 15 & 39 & 29 & 17 & 82 & 135 & 40 & 188 & 926 \\
\hline & & $2 / 2 / 2010$ & 58 & 17 & 33 & 29 & 17 & 78 & 123 & 42 & 188 & 934 \\
\hline
\end{tabular}


Table 2 Healthy Donor Sera Analysis (Continued)

\begin{tabular}{|c|c|c|c|c|c|c|c|c|c|c|c|c|}
\hline & & $5 / 13 / 2010$ & 64 & 15 & 37 & 32 & 21 & 76 & 144 & 38 & 160 & 815 \\
\hline & & $5 / 13 / 2010$ & 65 & 15 & 35 & 33 & 20 & 72 & 129 & 36 & 160 & 742 \\
\hline & & 8/11/2010 & 23 & $<3$ & 10 & 8 & $<10$ & 9 & 22 & 34 & 71 & 144 \\
\hline & & $8 / 11 / 2010$ & 32 & 6 & 14 & 14 & $<10$ & 21 & 36 & 34 & 96 & 130 \\
\hline \multirow[t]{6}{*}{ Healthy donor 9} & $12 / 24 / 2009$ & $2 / 2 / 2010$ & $<5$ & 9 & 17 & $<14$ & $<10$ & $<12$ & $<15$ & 21 & 13 & 969 \\
\hline & & 2/2/2010 & $<5$ & 8 & 15 & $<14$ & $<10$ & $<12$ & $<15$ & 20 & 20 & 928 \\
\hline & & $5 / 13 / 2010$ & $<5$ & $<8$ & 13 & $<14$ & $<10$ & $<12$ & $<15$ & 17 & $<12$ & 784 \\
\hline & & $5 / 13 / 2010$ & $<5$ & $<8$ & 14 & $<14$ & $<10$ & $<12$ & $<15$ & 19 & $<12$ & 813 \\
\hline & & $8 / 11 / 2010$ & 8 & 11 & 19 & 9 & $<10$ & 6 & $<15$ & 29 & 20 & 332 \\
\hline & & $8 / 11 / 2010$ & 7 & 10 & 17 & 8 & $<10$ & $<5$ & $<15$ & 26 & 20 & 331 \\
\hline \multirow[t]{6}{*}{ Healthy donor 10} & $12 / 28 / 2009$ & $2 / 2 / 2010$ & $<5$ & 8 & $<12$ & $<14$ & $<10$ & $<12$ & $<15$ & 37 & 13 & 1034 \\
\hline & & $2 / 2 / 2010$ & $<5$ & $<8$ & $<12$ & $<14$ & $<10$ & 16 & $<15$ & 37 & 13 & 990 \\
\hline & & $5 / 13 / 2010$ & $<5$ & $<8$ & $<12$ & $<14$ & $<10$ & $<12$ & $<15$ & 34 & $<12$ & 845 \\
\hline & & $5 / 13 / 2010$ & $<5$ & $<8$ & $<12$ & $<14$ & $<10$ & $<12$ & $<15$ & 36 & $<12$ & 802 \\
\hline & & $8 / 11 / 2010$ & $<5$ & 4 & $<3$ & $<5$ & $<10$ & $<5$ & $<15$ & 57 & 6 & 374 \\
\hline & & 8/11/2010 & 5 & 5 & $<3$ & $<5$ & $<10$ & 8 & $<15$ & 59 & 11 & 385 \\
\hline
\end{tabular}

times were plotted together (Figure 3), the trends in concentration changes observed were not significantly different between the serum sample data sets (old patients, HD, new patients) (Table 1, Table 2, Table 3).

\section{Cytokine Controls used in assays}

We purchased our Luminex kits from a single source, however, that source changed ownership between Oct. '05 and Aug. '10 (from Biosource to Invitrogen to Life

Table 3 New Melanoma Patient Sera Analysis

\begin{tabular}{|c|c|c|c|c|c|c|c|c|c|c|c|c|}
\hline Sample & $\begin{array}{l}\text { Draw } \\
\text { Date }\end{array}$ & $\begin{array}{c}\text { Assay } \\
\text { Date }\end{array}$ & $\begin{array}{c}\mathrm{IL}-4 \\
\mathrm{pg} / \mathrm{mL}\end{array}$ & $\begin{array}{c}\text { IL-6 } \\
\mathrm{pg} / \mathrm{mL}\end{array}$ & $\begin{array}{c}\mathrm{IL}-8 \\
\mathrm{pg} / \mathrm{mL}\end{array}$ & $\begin{array}{c}\mathrm{IL}-10 \\
\mathrm{pg} / \mathrm{mL}\end{array}$ & $\begin{array}{l}\text { TNF- } \alpha \\
\mathrm{pg} / \mathrm{mL}\end{array}$ & $\begin{array}{l}\text { IFN-g } \\
\mathrm{pg} / \mathrm{mL}\end{array}$ & $\begin{array}{l}\text { GM-CSF } \\
\mathrm{pg} / \mathrm{mL}\end{array}$ & $\begin{array}{c}\text { IP-10 } \\
\mathrm{pg} / \mathrm{mL}\end{array}$ & $\begin{array}{c}\mathrm{MIG} \\
\mathrm{pg} / \mathrm{mL}\end{array}$ & $\begin{array}{l}\mathrm{MCP}-1 \\
\mathrm{pg} / \mathrm{mL}\end{array}$ \\
\hline \multirow[t]{4}{*}{ Mel. Pt. 1} & $5 / 10 / 2010$ & $5 / 13 / 2010$ & 15 & 11 & 42 & $<14$ & 95 & 24 & $<15$ & 39 & 12 & 754 \\
\hline & $5 / 10 / 2010$ & $5 / 13 / 2010$ & 10 & 8 & 39 & $<14$ & 82 & 22 & $<15$ & 40 & 17 & 754 \\
\hline & $5 / 10 / 2010$ & $8 / 11 / 2010$ & 21 & 12 & 44 & 22 & 183 & 20 & 41 & 49 & 32 & 270 \\
\hline & $5 / 10 / 2010$ & $8 / 11 / 2010$ & 24 & 13 & 43 & 29 & 168 & 23 & 51 & 50 & 32 & 268 \\
\hline \multirow[t]{4}{*}{ Mel. Pt. 2} & $5 / 10 / 2010$ & $5 / 13 / 2010$ & 18 & 17 & 87 & $<14$ & $<10$ & 26 & $<15$ & 30 & 21 & 1437 \\
\hline & $5 / 10 / 2010$ & $5 / 13 / 2010$ & 13 & 16 & 95 & $<14$ & $<10$ & 21 & $<15$ & 31 & 17 & 1494 \\
\hline & $5 / 10 / 2010$ & $8 / 11 / 2010$ & 28 & 30 & 97 & 22 & 10 & 25 & 33 & 38 & 39 & 664 \\
\hline & $5 / 10 / 2010$ & $8 / 11 / 2010$ & 25 & 31 & 86 & 24 & 10 & 24 & 30 & 37 & 28 & 662 \\
\hline \multirow[t]{4}{*}{ Mel. Pt. 3} & $5 / 10 / 2010$ & $5 / 13 / 2010$ & 42 & 21 & 72 & 29 & 20 & $<12$ & 18 & 190 & 81 & 771 \\
\hline & $5 / 10 / 2010$ & $5 / 13 / 2010$ & 38 & 19 & 70 & 25 & 17 & $<12$ & 18 & 188 & 78 & 732 \\
\hline & $5 / 10 / 2010$ & $8 / 11 / 2010$ & 34 & 14 & 73 & 31 & 38 & 9 & 47 & 141 & 96 & 223 \\
\hline & $5 / 10 / 2010$ & $8 / 11 / 2010$ & 36 & 15 & 70 & 28 & 32 & 6 & 50 & 135 & 89 & 198 \\
\hline \multirow[t]{4}{*}{ Mel. Pt. 4} & $5 / 10 / 2010$ & $5 / 13 / 2010$ & 68 & 26 & 45 & 51 & 19 & 62 & 107 & 19 & 145 & 955 \\
\hline & $5 / 10 / 2010$ & $5 / 13 / 2010$ & 66 & 24 & 42 & 53 & 18 & 63 & 111 & 18 & 143 & 875 \\
\hline & $5 / 10 / 2010$ & $8 / 11 / 2010$ & 102 & 36 & 26 & 120 & $<10$ & 16 & 50 & 19 & 100 & 238 \\
\hline & $5 / 10 / 2010$ & $8 / 11 / 2010$ & 99 & 41 & 24 & 139 & $<10$ & 16 & 48 & 20 & 103 & 215 \\
\hline \multirow[t]{4}{*}{ Mel. Pt. 5} & $5 / 10 / 2010$ & $5 / 13 / 2010$ & 35 & 64 & 380 & $<14$ & 13 & 27 & 78 & 27 & 106 & 831 \\
\hline & $5 / 10 / 2010$ & $5 / 13 / 2010$ & 34 & 61 & 393 & $<14$ & 10 & 27 & 82 & 26 & 101 & 737 \\
\hline & $5 / 10 / 2010$ & $8 / 11 / 2010$ & 33 & 43 & 458 & 20 & 16 & 27 & 54 & 32 & 139 & 170 \\
\hline & $5 / 10 / 2010$ & $8 / 11 / 2010$ & 45 & 53 & 480 & 25 & 24 & 34 & 55 & 38 & 146 & 222 \\
\hline
\end{tabular}




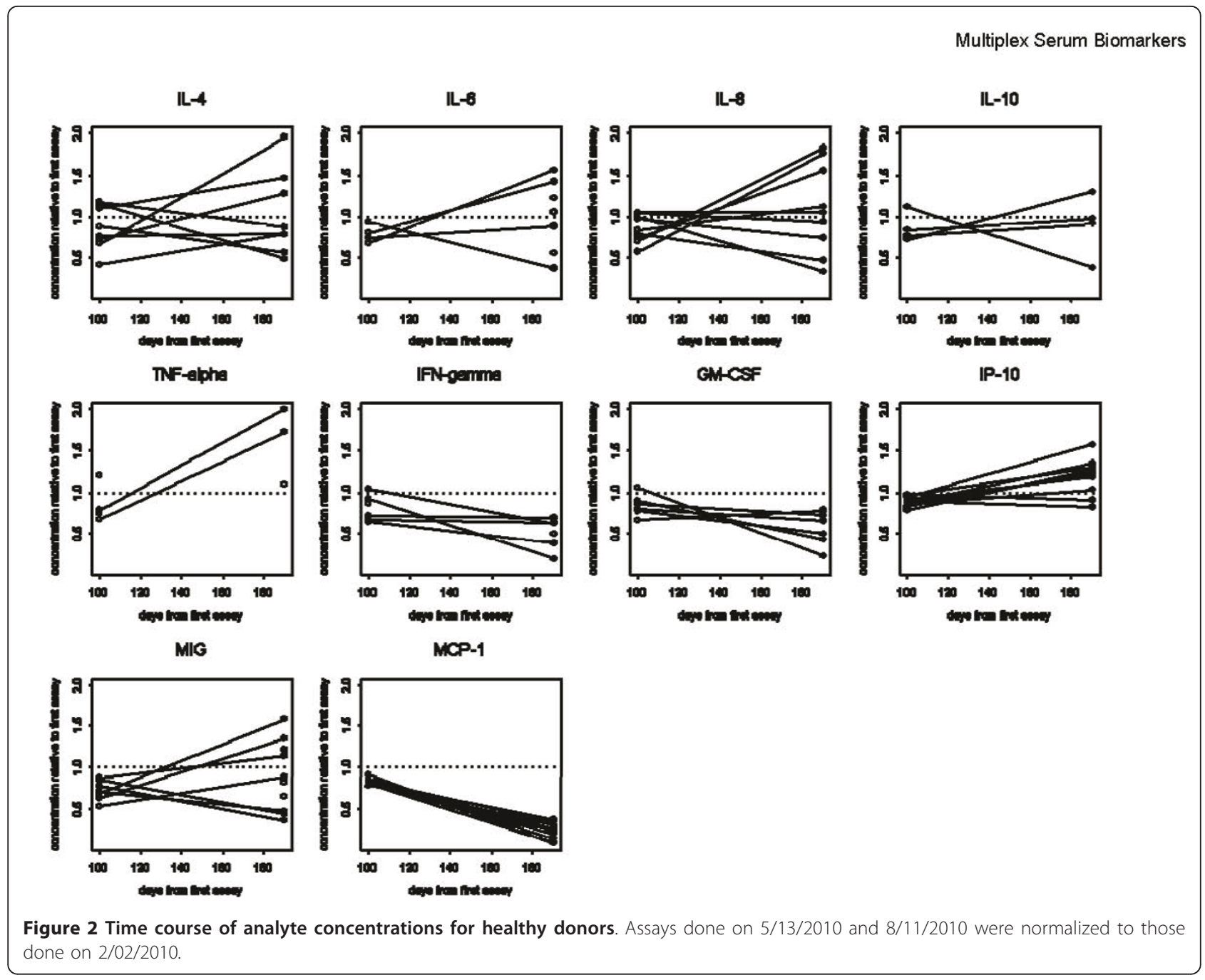

Technologies). Each kit includes reagents to generate an 8 -point standard curve from which all values are determined. For the custom kits we requested, to test a specific array of analytes of interest, the manufacturer pretests the specific antibodies together, to confirm lack of cross-reactivity. The manufacturer indicates that the kits are not released unless the following criteria are met: " $<10 \%$ cross-reactivity to related recombinant protein at the highest point of the standard curve" (Life Technologies). We requested the specific cross-reactivity testing data performed for the kits we used in this study, but were repeatedly informed that company policy prohibits QC data release to customers.

As an additional control, we included "Multiplex QC" controls, which are complex mixtures of recombinant cytokines, chemokines and growth factors prepared by the manufacturer at 3 concentrations (low, medium and high). We have established the reproducibility of this control (Additional File 4, Table S4) when tested via
Luminex (\% CV $=1 \%-52 \%$, average $\% \mathrm{CV}=14 \%$ for 8 analytes). While the absolute values for each analyte do not exactly match the "expected" value from the QC control manufacturer (R\&D Systems), they are similar, and we use a different platform and different antibody clones for detection via Luminex, which may account for those differences (as indicated in the package insert).

We also received WHO cytokine standards for IL-4, IL-8, IL-10 and GM-CSF. These lyophilized cytokine controls were resuspended (Materials and Methods) and individually tested at 1:10, 1:50 and 1:100 dilutions in two replicate Luminex assays for the same ten analytes described above. These data are presented in Table 4 . As expected, the standard under study was almost always detected. However, there were some surprising results. MCP-1 was also almost always detected in addition to the standard, and MIG was always detected when the standard IL-10 was used. The apparent concentrations of these two analytes in some instances 


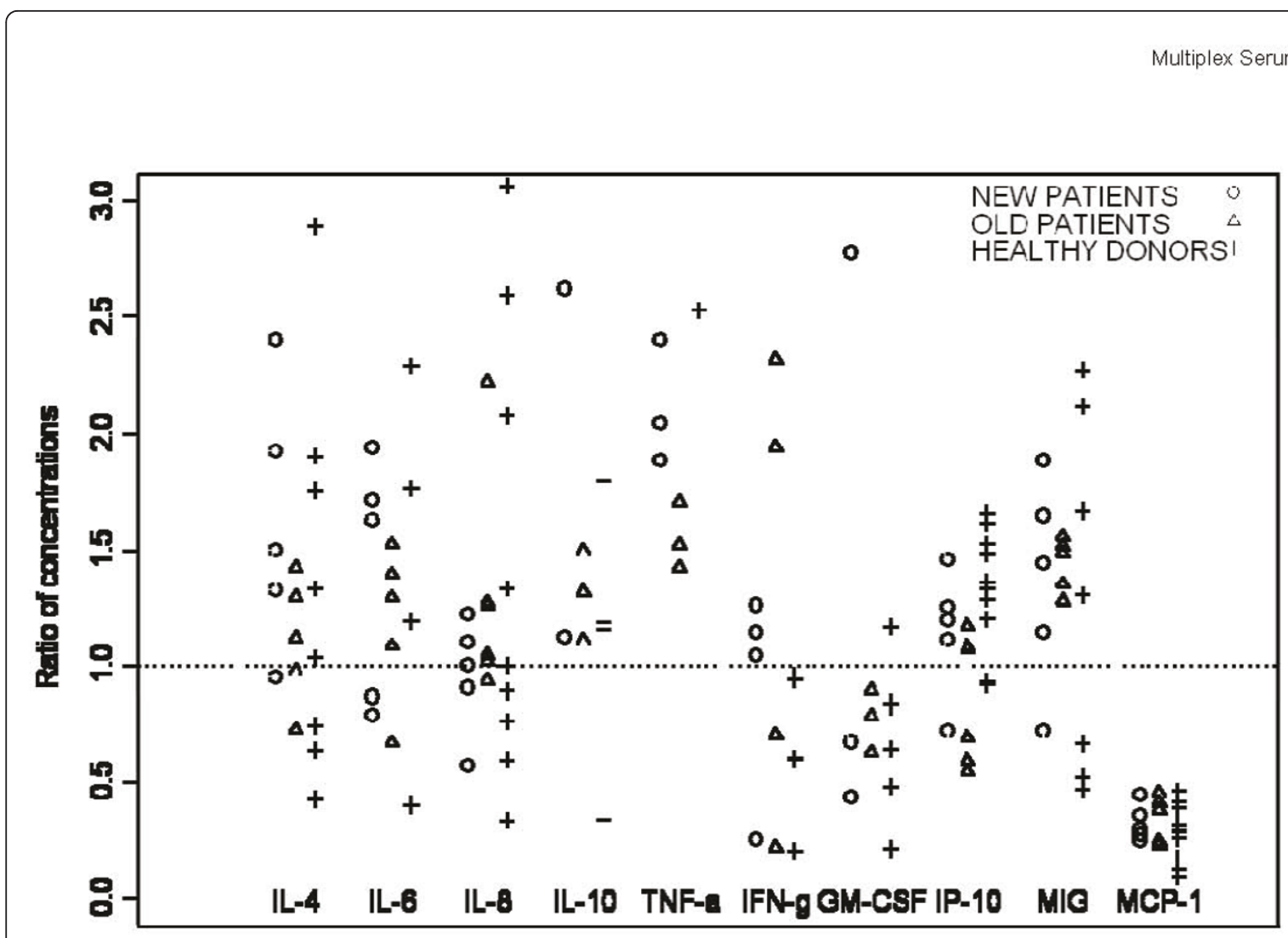

Figure 3 Comparison of assay results obtained with sera from healthy donors, new melanoma patients and old melanoma patients. Points are the ratio of concentrations of the assays done on 8/11/2010 normalized to those done on 5/13/2010.

exceeded $10 \%$ of that of the standard. IL-6, IFN- $\gamma$ and GM-CSF also showed evidence of minor cross-reactivity.

The apparent cross-reactivity seen for MCP-1 and MIG might be caused by a medium additive present in the AIM V medium (a serum-free lymphocyte culture medium) used in a dilution step for these proteins. We tested several commonly used culture medias (AIM V, RPM1640, Iscoves and CellGenix DC media) in a 30plex Luminex assay which also included a repeat test of the WHO standards. The results did identify low levels (3-62 $\mathrm{pg} / \mathrm{mL}$ ) of several analytes in the culture medias (HGF, FGF basic, RANTES, IL-17 and IL2R) but not MCP-1 or MIG (data not shown). The MCP-1 was again detected in the IL-8 and GM-CSF WHO standards and MIG in the IL-10 standard (as well as HGF, FGF basic and RANTES). We are investigating other possible sources of low levels of other cytokines and growth factors in the WHO standards.

As a test of the day-to-day reproducibility of two of the cytokines of particular interest, IL- 6 and IL-8, a set of samples and controls were run in two different custom kits one day apart (with samples kept thawed, at $4^{\circ}$ C overnight), in which both IL-6 and IL-8 were included in both kits. Notably, these two kits also had different standard curves and upper limits of detection. For IL-6, the 10-plex kit upper limit was $7,400 \mathrm{pg} / \mathrm{mL}$, while in the 8 -plex, it was $13,800 \mathrm{pg} / \mathrm{mL}$ (1.8 fold higher). For IL-8, the 10-plex upper limit was $24,800 \mathrm{pg} / \mathrm{mL}$ and in the 8 -plex, 10, $160 \mathrm{pg} / \mathrm{mL}$ (2.4 fold lower). When the values for the 38 samples were compared between the two kits, the ratio of the IL- 6 values was 1.0 (median \& mean), showing excellent concordance. For IL-8, where the upper limits were more disparate, the ratio of the values was 0.80 , which was a small but significant difference (Figures $4 \mathrm{~A}$ and $4 \mathrm{~B}$ ). These data indicate that the assay with the higher upper limit has larger measured values.

\section{Upper limit problem}

The Luminex kits that we used at the different time points were not identical. In particular, we noticed that the upper limits of quantitation for individual analytes changed over time for the different kits. In principal, this should not affect the measured concentrations, because the kits include kit-specific standards to generate 8-point standard curves matched to the expected 
Table 4 WHO Cytokine Standards

\begin{tabular}{|c|c|c|c|c|c|c|c|c|c|c|c|}
\hline Lab Number & $\begin{array}{l}\text { Assay } \\
\text { Date }\end{array}$ & $\begin{array}{c}\mathrm{IL}-4 \\
\mathrm{pg} / \mathrm{mL}\end{array}$ & $\begin{array}{c}\mathrm{IL}-6 \\
\mathrm{pg} / \mathrm{mL}\end{array}$ & $\begin{array}{c}\mathrm{IL}-8 \\
\mathrm{pg} / \mathrm{mL}\end{array}$ & $\begin{array}{l}\mathrm{IL}-10 \\
\mathrm{pg} / \mathrm{mL}\end{array}$ & $\begin{array}{l}\text { TNF- } \alpha \\
\mathrm{pg} / \mathrm{mL}\end{array}$ & $\begin{array}{l}\text { IFN-g } \\
\mathrm{pg} / \mathrm{mL}\end{array}$ & $\begin{array}{l}\text { GM-CSF } \\
\mathrm{pg} / \mathrm{mL}\end{array}$ & $\begin{array}{l}\mathrm{IP}-10 \\
\mathrm{pg} / \mathrm{mL}\end{array}$ & $\begin{array}{c}\mathrm{MIG} \\
\mathrm{pg} / \mathrm{mL}\end{array}$ & $\begin{array}{l}\mathrm{MCP}-1 \\
\mathrm{pg} / \mathrm{mL}\end{array}$ \\
\hline \multicolumn{12}{|l|}{117173 IL-4 } \\
\hline $1: 10$ & 40311 & 17497 & N/A & N/A & N/A & N/A & N/A & N/A & N/A & N/A & N/A \\
\hline $1: 10$ & 40401 & 11364 & N/A & N/A & N/A & N/A & N/A & N/A & N/A & N/A & 196 \\
\hline $1: 10$ & 40401 & 10956 & N/A & N/A & N/A & N/A & N/A & N/A & N/A & N/A & 114 \\
\hline $1: 50$ & 40311 & 10945 & N/A & N/A & N/A & N/A & N/A & N/A & N/A & N/A & N/A \\
\hline $1: 50$ & 40401 & 1350 & N/A & N/A & N/A & N/A & N/A & N/A & N/A & N/A & 392 \\
\hline $1: 50$ & 40401 & 1321 & N/A & N/A & $\mathrm{N} / \mathrm{A}$ & N/A & N/A & N/A & N/A & N/A & 1220 \\
\hline \multicolumn{12}{|l|}{117177 IL-8 } \\
\hline 1:10 & 40311 & N/A & N/A & 216983 & N/A & N/A & N/A & N/A & N/A & N/A & N/A \\
\hline $1: 10$ & 40401 & N/A & N/A & 153880 & N/A & N/A & N/A & N/A & N/A & N/A & 563 \\
\hline $1: 10$ & 40401 & N/A & N/A & 153707 & N/A & N/A & N/A & N/A & N/A & N/A & 509 \\
\hline $1: 50$ & 40311 & N/A & N/A & QA & N/A & N/A & N/A & N/A & N/A & N/A & N/A \\
\hline $1: 50$ & 40401 & N/A & N/A & 45621 & N/A & N/A & N/A & N/A & N/A & N/A & 2169 \\
\hline $1: 50$ & 40401 & N/A & N/A & 46708 & N/A & N/A & N/A & N/A & N/A & N/A & 1445 \\
\hline \multicolumn{12}{|l|}{117184 IL-10 } \\
\hline $1: 10$ & 40311 & N/A & N/A & N/A & 119338 & N/A & N/A & 180 & N/A & 1813 & N/A \\
\hline $1: 10$ & 40401 & N/A & 230 & N/A & 72096 & N/A & N/A & N/A & N/A & 3621 & 318 \\
\hline $1: 10$ & 40401 & N/A & 226 & N/A & 95800 & N/A & N/A & N/A & N/A & 3891 & 389 \\
\hline $1: 50$ & 40311 & N/A & N/A & N/A & 95462 & N/A & N/A & N/A & N/A & 3836 & N/A \\
\hline $1: 50$ & 40401 & N/A & 340 & N/A & 39419 & N/A & N/A & N/A & N/A & 4488 & 1855 \\
\hline $1: 50$ & 40401 & $\mathrm{~N} / \mathrm{A}$ & 179 & $\mathrm{~N} / \mathrm{A}$ & 30223 & N/A & N/A & N/A & $\mathrm{N} / \mathrm{A}$ & 4053 & 1308 \\
\hline \multicolumn{12}{|l|}{ 117187GM-CSF } \\
\hline $1: 10$ & 40401 & $\mathrm{~N} / \mathrm{A}$ & $\mathrm{N} / \mathrm{A}$ & $\mathrm{N} / \mathrm{A}$ & $\mathrm{N} / \mathrm{A}$ & $\mathrm{N} / \mathrm{A}$ & 373 & 75824 & N/A & N/A & 875 \\
\hline $1: 10$ & 40401 & N/A & N/A & N/A & N/A & N/A & 272 & 70453 & N/A & N/A & 721 \\
\hline $1: 10$ & 40311 & N/A & N/A & N/A & N/A & N/A & N/A & 47332 & N/A & N/A & N/A \\
\hline $1: 10$ & 40311 & N/A & $\mathrm{N} / \mathrm{A}$ & N/A & N/A & N/A & N/A & 78882 & N/A & N/A & 769 \\
\hline $1: 50$ & 40311 & N/A & N/A & $\mathrm{N} / \mathrm{A}$ & N/A & $\mathrm{N} / \mathrm{A}$ & N/A & 59603 & $\mathrm{~N} / \mathrm{A}$ & N/A & N/A \\
\hline $1: 50$ & 40311 & N/A & N/A & N/A & N/A & N/A & N/A & 76623 & N/A & N/A & 1063 \\
\hline $1: 50$ & 40311 & N/A & N/A & N/A & N/A & N/A & N/A & 19209 & N/A & N/A & 1193 \\
\hline
\end{tabular}

detection range. However, if the concentration determinations were affected, that would confound our interpretation of the observed changes in analyte concentration over time, and therefore we investigated that possibility. Data from assays done on 5/13/2010 ("late" assay) were compared to data from assays on $10 /$ $31 / 2005,11 / 1 / 2005$ or 2/17/2006 ("early" assays). Kits used in 2005 and 2006 had the same upper limits, and because no samples had assays done on the same date, results were combined. Figure 5 is a scatter plot of the late-to-early ratio of analyte concentrations versus the late-to-early ratio of assay upper limits assays with a smooth curve is superimposed. The late-to-early ratio of upper limits was different for each of the 10 analytes. Typically, 12 samples were assessed for each analyte. The correlation of the two ratios is highly significant ( $p$ $<10^{-15}$, Spearman's test). Therefore, we are concerned that assays performed at different times with different kits may not be comparable.

In this report, we detail reproducibility problems we encountered testing circulating cytokines, chemokines and growth factors by Luminex in serum samples which were stored over months to years under highly controlled conditions. Some of these changes were very dramatic: IL-8 increased 4-6 fold in old patient samples; MCP-1 decreased 4-6 fold in new patient samples, and up to 10 -fold in healthy donor samples; IL-10 changed from negative to positive or positive to negative within the same old patient serum dataset (Figure 1). Our initial hypothesis was that the changes were entirely biological, and that despite standardized blood handling procedures and temperature-controlled freezer storage, some analytes became unstable over time or upon thaw. Two recent reports testing cytokine stability found most 
A

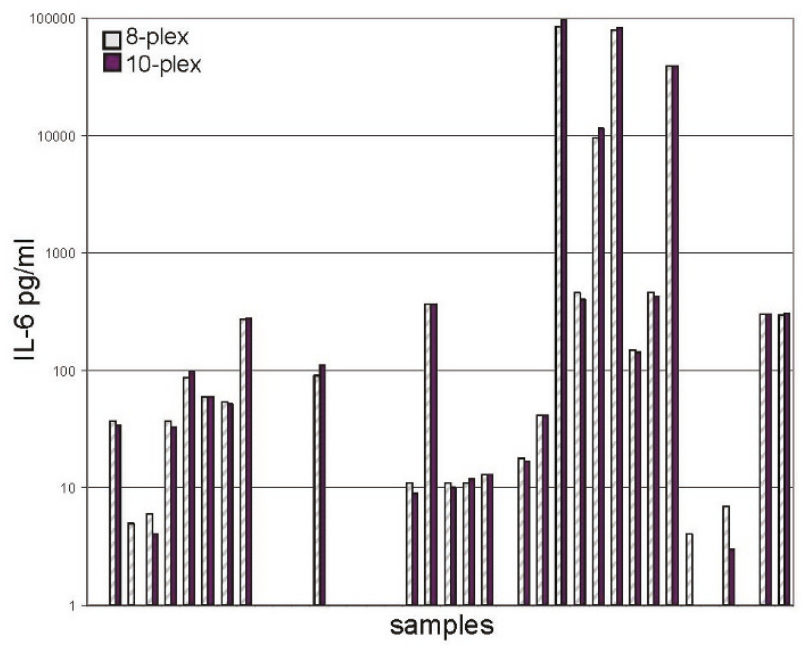

B

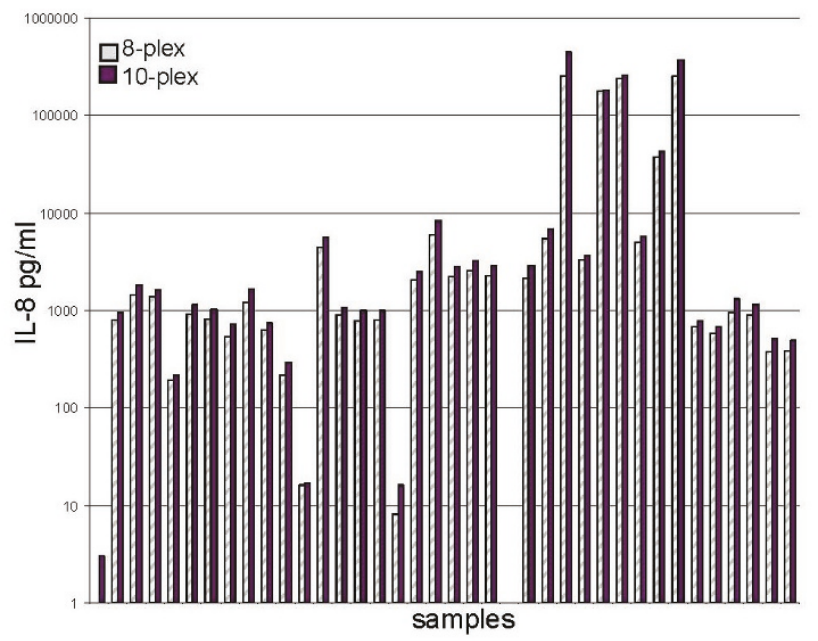

Figure 4 Two plates run together compared for A) IL-6 and B) IL-8 values. A set of 38 cell culture samples were run on both an 8-plex and a 10-plex plate. The values for IL-6 and IL-8 are compared on a log scale. Each plate had a unique upper limit. The values for IL-6 show excellent concordance, and the 8 -plex upper limit was 1.8 times the upper limit. The IL-8 values were reproducibly higher (1.25x) in the $10-$ plex plate where the upper limit was 2.4 times higher.

tested cytokines to be stable over $1-2$ years at $-80^{\circ} \mathrm{C}$, and a subset (including IL-8 and IL-10) became unstable after $2-4$ years $[24,25]$. Many of the proteins became unstable after repeated freeze-thaw cycles. If these were the only mechanisms, then the analytes we tested should have behaved consistently between our three datasets, because the change would be analyte-specific. This is not the only

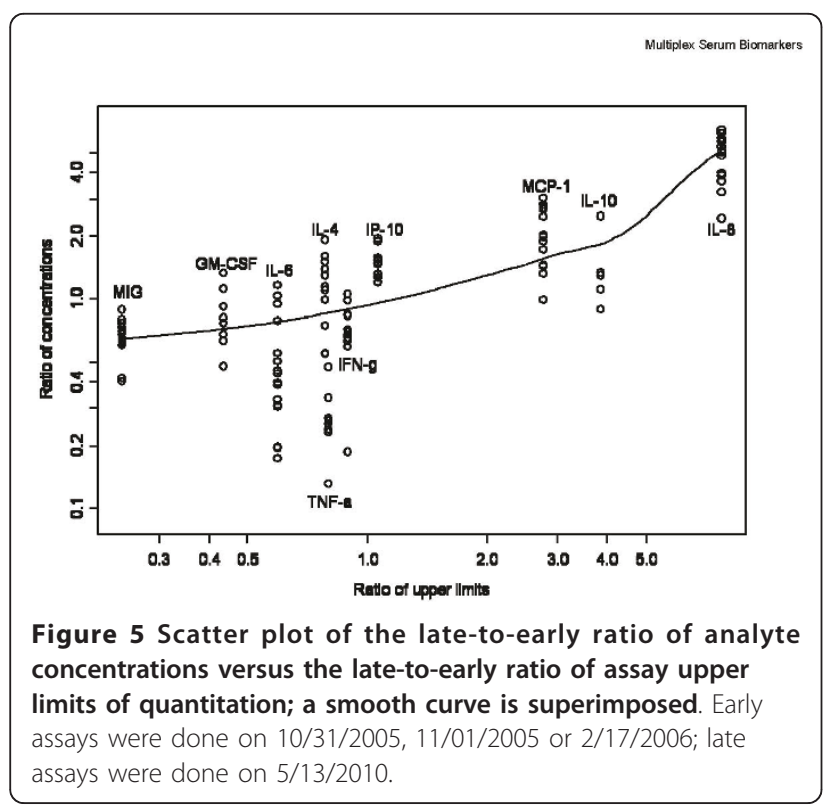

explanation, because, for example, MCP-1 increased over time in the majority of old patient samples and decreased over time in both HD and new patient sets.

Our study has a number of limitations. The more recently acquired $\mathrm{HD}$ and new patient data sets were tested within months of blood draw. A better analysis of the impact of storage time on analyte stability would require a large number of patients and HD samples stored for longer periods with costly repeated multiplex testing. We also limited the diversity of analytes we examined. Another variable was the time from blood draw to serum separation and freezing. Some of our samples were drawn within the laboratory and at our nearby clinic and processed within a few hours, while other old patient samples were shipped overnight and processed the following morning. However, the nature of these blood handling procedures reflects the unavoidable limitations inherent in transferring patient blood from the clinic to a central laboratory capable of standardized processing, as well as for multi-institutional trials where large numbers of patients can be treated and tested, but overnight shipping is required. Lastly, some of our healthy donor and control samples were run in duplicate, but to reduce costs, large numbers of patient sera were run in singlets. Due to the small average \% CVs determined for many duplicates (Additional File 1, Table S1) this may have minimal impact on the trends we observed. 
The Luminex assay has been shown (by ourselves [26] and others [27]) to show good correspondence to ELISA platform assays. In addition, the Luminex assay has good reproducibility from well-to-well, and from day-today (Figure 4). Also, our use of the R\&D QC controls (Additional File 4, Table S4) indicate good reproducibility of recombinant analytes when mixed together. This may indicate that the serum matrix may impact reproducibility, and/or the biological impact of a tumor may lead to systemic changes (including altered glycosylation) which impact the assay.

This study also suggests that the changes in the upper limits of detection, which can vary substantially from kit to kit, month to month, and analyte to analyte from a single manufacturer, may impact the ability to determine analyte concentration. This impacts kit-to-kit reproducibility, and greatly increases the importance of comparing samples with the identical lot of kits with identical standard curve ranges. We attempted to dissect this further by requesting access to manufacturer QC data, but we were repeatedly denied access to any additional information specific to the testing performed on the kits we used.

We do not understand why the assay kit upper limits seem to affect assay performance in the systematic way that is evident in Figure 5. However, we have to conclude that the results of assays done with different kits cannot be directly compared. Therefore, the apparent changes in analyte levels over time that we observe may arise from the kit-to-kit variability: we cannot claim to observe changes in analyte levels over storage time at $-80^{\circ} \mathrm{C}$.

\section{Conclusions}

In conclusion, the multiplex Luminex platform offers the opportunity to test a wide variety of analytes in the same sample, with minimal volume requirements, and good well-to-well and day-to-day reproducibility. These attributes are important when broadly searching for serum biomarkers. However, we find that a number of commonly tested candidate immunologic biomarkers show evidence of unexpected, large variability when tested retrospectively, after long storage times. This variability can be reduced by 1) performing assays with kits from a single lot, and potentially 2) minimizing storage time before retrospective analysis of banked serum.

\section{Additional material}

Additional file 1: Table S1: Luminex kit details. This table includes upper and lower limits of detection and \%CVs.

Additional file 2: Table S2: Healthy Donor Demographics. This table includes age, race and gender information.
Additional file 3: Table S3: New Melanoma Patient Demographics.

This table includes age, race, gender and treatment information.

Additional file 4: Table S4: R\&D Systems QC Control Data. This table includes control sample values and \%CVs.

\section{List of Abbreviations}

IL: interleukin; TNF: tumor necrosis factor; GM-CSF: granulocyte-macrophage colony stimulating factor; PBMC: peripheral blood mononuclear cells; FDA: Food and Drug Administration; FBS: fetal bovine serum.

\section{Acknowledgements and funding}

We acknowledge Sharon Sember (IML) for conduct of the Luminex assays (UPCI IML), and Dr. Theresa L. Whiteside (University of Pittsburgh) for helpful discussions.

This study was supported in part by the University of Pittsburgh Cancer Institute and the NIH Cancer Center Support Grant P30 CA047904; NCI RO1 CA138635 (LHB); Developmental Research Funds of the SPORE in Skin Cancer P50 CA121973 (JMK); Frontier Science and Technology Research Foundation and ECOG Central Laboratory Support (LHB).

\section{Author details}

${ }^{1}$ University of Pittsburgh Cancer Institute, 5117 Centre Avenue, suite 1.27, Pittsburgh, PA 15213, USA. ${ }^{2}$ University of Pittsburgh School of Medicine, 5117 Centre Avenue, suite 1.27, Pittsburgh, PA 15213, USA. ${ }^{3}$ Department of Medicine, University of Pittsburgh, 5117 Centre Avenue, suite 1.27, Pittsburgh, PA 15213, USA. "Department of Surgery, University of Pittsburgh, 5117 Centre Avenue, suite 1.27, Pittsburgh, PA 15213, USA. ${ }^{5}$ Department of Immunology, University of Pittsburgh, 5117 Centre Avenue, suite 1.27, Pittsburgh, PA 15213, USA. ${ }^{6}$ Depament of Biostatistics, University of Pittsburgh, 5117 Centre Avenue, suite 1.27, Pittsburgh, PA 15213, USA.

\section{Authors' contributions}

LHB designed experiments, reviewed data, supervised assay conduct and wrote sections of the manuscript; DMP helped design experiments, designed and performed all statistical analyses and wrote sections of the manuscript; JMK provided many patient blood samples, reviewed data and wrote sections of the manuscript. All authors read and approved the final manuscript.

\section{Competing interests}

The authors declare that they have no competing interests.

Received: 15 June 2011 Accepted: 11 October 2011

Published: 11 October 2011

\section{References}

1. Dancey JE, Dobbin KK, Groshen S, Jessup JM, Hruszkewycz AH, Koehler M, Parchment R, Ratain MJ, Shankar LK, Stadler WM, True LD, Gravell A, Grever MR, Biomarkers Task Force of the NCl Investigational Drug Steering Committee: Guidelines for the development and incorporation of biomarker studies in early clinical trials of novel agents. Clin Cancer Res 2010, 16:1745-55.

2. Kirkwood JM, Manola J, Ibrahim J, Sondak V, Ernstoff MS, Rao U, Eastern Cooperative Oncology Group: A pooled analysis of eastern cooperative oncology group and intergroup trials of adjuvant high-dose interferon for melanoma. Clin Cancer Res 2004, 10:1670-1677.

3. Rosenberg SA, Restifo NP, Yang JC, Morgan RA, Dudley ME: Adoptive cell transfer: a clinical path to effective cancer immunotherapy. Nat Rev Cancer 2008, 8:299-308.

4. Butterfield LH, Disis ML, Fox BA, Lee PP, Khleif SN, Thurin M, Trinchieri G, Wang E, Wigginton J, Chaussabel D, Coukos G, Dhodapkar M, Hakansson L, Janetzki S, Kleen TO, Kirkwood JM, Maccalli C, Maecker H, Maio M, Malyguine A, Masucci G, Palucka AK, Potter DM, Ribas A, Rivoltini L, Schendel D, Seliger B, Selvan S, Slingluff CL, Stroncek DF, Streicher H, Wu X, Zeskind B, Zhao Y, Zocca M-B, Zwierzina H, Marincola FM: A systematic approach to biomarker discovery; Preamble to "the iSBTc-FDA taskforce on immunotherapy biomarkers. J Trans/ Med 2008, 6:81. 
5. Tahara $H$, Sato $M$, Thurin $M$, Wang $E$, Butterfield LH, Disis ML, Fox BA, Lee PP, Khleif SN, Wigginton JM, Ambs S, Akutsu Y, Chaussabel D, Doki Y, Eremin $O$, Fridman WH, Hirohashi $Y$, Imai K, Jacobson J, Jinushil M, Kanamoto A, Kashani-Sabet M, Kato K, Kawakami Y, Kirkwood JM, Kleen TO, Lehmann PV, Liotta L, Lotze MT, Malyguine A, Masucci G, Matsubara H, Nakamura K, Nishikawa H, Palucka AK, Petricoin EF, Pos Z, Ribas A, Rivoltini L, Sato N, Shiku H, Slingluff CL, Streicher H, Stronchek DF, Takeuchi H, Toyota M, Wada H, Wu X, Wulfkuhle J, Yaguchi T, Zeskind B, Zhao $Y$, Zocca M-B, Marincola FM: Emerging concepts in biomarker discovery: The US-Japan workshop on immunological molecular markers in oncology. J Transl Med 2009, 7:45.

6. Butterfield LH, Disis ML, Khleif SN, Balwit JM, Marincola F: Immunooncology biomarkers 2010 and beyond: Perspectives from the iSBTc/ SITC Biomarker Task Force. J Transl Med 2010, 8:130.

7. Butterfield LH, Palucka AK, Britten CM, Dhodapkar MV, Hakansson L, Janetzki S, Kawakami Y, Kleen T-O, Lee PP, Macalli C, Maecker HT, Maino VC, Maio M, Malyguine A, Masucci G, Pawelec G, Potter DM, Rivoltini L, Salazar LG, Schendel DJ, Slingluff CL Jr, Song W, Stroncek DF, Tahara H, Thurin M, Trinchieri G, van Der Burg SH, Whiteside TL, Wigginton JM, Marincola F, Khleif S, Fox BA, Disis ML: Recommendations from the iSBTcSITC/FDA/NCI Workshop on Immunotherapy Biomarkers. Clin Cancer Res 2011, 17:3064-3076.

8. Yurkovetsky ZR, Kirkwood JM, Edington HD, Marrangoni AM, Velikokhatnaya L, Winans MT, Gorelik E, Lokshin AE: Multiplex analysis of serum cytokines in melanoma patients treated with interferon-alpha2b. Clin Cancer Res 2007, 13:2422-2428.

9. Hutchinson PE, Osborne JE, Pringle JH: Higher serum 25-hydroxy vitamin D3 levels at presentation are associated with improved survival from melanoma, but there is no evidence that later prevailing levels are protective. J Clin Oncol 2010, 28:e492-493.

10. Gajewski TF, Fuertes M, Spaapen R, Zheng $Y$, Kline J: Molecular profiling to identify relevant immune resistance mechanisms in the tumor microenvironment. Curr Opin Immunol 2011, 23:286-292.

11. Ma J, Lin JY, Alloo A, Wilson BJ, Schatton T, Zhan Q, Murphy GF, WaagaGasser AM, Gasser M, Stephen Hodi F, Frank NY, Frank MH: Isolation of tumorigenic circulating melanoma cells. Biochem Biophys Res Commun 2010, 402:711-717

12. Liu Y, He J, Xie X, Su G, Teitz-Tennenbaum S, Sabel MS, Lubman DM: Serum autoantibody profiling using a natural glycoprotein microarray for the prognosis of early melanoma. J Proteome Res 2010, 9:6044-6051.

13. Kirkwood JM, Lee S, Moschos SJ, Albertini MR, Michalak JC, Sander C, whiteside $T L$, Butterfield LH, Weiner L: Immunogenicity and antitumor effects of vaccination with peptide vaccine+/-granulocyte-monocyte colony-stimulating factor and/or IFN-alpha2b in advanced metastatic melanoma: Eastern Cooperative Oncology Group Phase II Trial E1696. Clin Cancer Res 2009, 15:1443-1451.

14. Gould Rothberg BE, Rimm DL: Biomarkers: the useful and the not so useful-an assessment of molecular prognostic markers for cutaneous melanoma. J Invest Dermatol 2010, 130:1971-1987.

15. Hodi FS, Dranoff G: The biologic importance of tumor-infiltrating lymphocytes. J Cutan Pathol 2010, 37(Suppl 1):48-53.

16. Bull M, Lee D, Stucky J, Chiu YL, Rubin A, Horton H, McElrath MJ: Defining blood processing parameters for optimal detection of cryopreserved antigen-specific responses for HIV vaccine trials. J Immunol Meth 2007 322:57-69.

17. Kierstead LS, Dubey S, Meyer B, Tobery TW, Mogg R, Fernandez VR, Long R, Guan L, Gaunt C, Collins K, Sykes K, Mehrotra DV, Chirmule N, Shiver JW, Casimiro DR: Enhanced rates and magnitude of immune responses detected against an HIV vaccine: effect of using an optimized process for isolating PBMC. AIDS Res Hum Retroviruses 2007, 23:86-92.

18. McKenna KC, Beatty KM, Bilonick RA, Schoenfield L, Lathrop KL, Singh AD: Activated CD11b+CD15+ granulocytes increase in the blood of patients with uveal melanoma. Invest Ophthalmol Vis Sci 2009, 50:4295-4303.

19. Boaz MJ, Hayes $P$, Tarragona T, Seamons L, Cooper A, Birungi J, Kitandwe $P$, Semaganda A, Kaleebu P, Stevens G, Anzala O, Farah B, Ogola S, Indangasi J, Mhlanga P, Van Eeden M, Thakar M, Pujari A, Mishra S, Goonetilleke N, Moore S, Mahmoud A, Sathyamoorthy P, Mahalingam J, Narayanan PR, Ramanathan VD, Cox JH, Dally L, Gill DK, Gilmour J: Concordant proficiency in measurement of T-cell immunity in human immunodeficiency virus vaccine clinical trials by peripheral blood mononuclear cell and enzyme-linked immunospot assays in laboratories from three continents. Clin Vacc Immunol 2009, 16:147-155.

20. Clinical Laboratory Improvement Amendments (CLIA) Brochures. [http:// www.cms.hhs.gov/CLIA/].

21. International Conference on Harmonisation of Technical Requirements for Registration of Pharmaceuticals for Human Use (ICH). [http://www.ich. org].

22. FDA Food and Drug Administration: Draft Guidance for Industry: Potency Tests for Cellular and Gene Therapy Products. [http://www.fda. gov/BiologicsBloodVaccines/GuidanceComplianceRegulatorylnformation/ Guidances/CellularandGeneTherapy/ucm072571.htm].

23. Potter DM, Butterfield LH, Divito SJ, Sander C, Kirkwood JM: Pitfalls in retrospective analyses of biomarkers: a case study with metastatic melanoma patients. 2011.

24. de Jager W, Bourcier K, Rijkers GT, Prakken BJ, Seyfert-Margolis V: Prerequisites for cytokine measurements in clinical trials with multiplex immunoassays. BMC Immunol 2009, 10:52.

25. Zhou XB, Fragala MS, McElhaney JEB, Kuchel GA: Conceptual and methodological issues relevant to cytokine and inflammatory marker measurements in clinical research. Curr Opin Clin Nutr Metabolic Care 2010, 13:541-547.

26. Butterfield LH, Gooding W, Whiteside TL: Development of a potency assay for human dendritic cells: IL-12p70 production. J Immunother 2008, 31:89-100

27. Khan SS, Smith MS, Reda D, Suffredini AF, McCoy JP Jr: Multiplex bead array assays for detection of soluble cytokines: comparisons of sensitivity and quantitative values among kits from multiple manufacturers. Cytometry B Clin Cytom 2004, 61:35-39.

doi:10.1186/1479-5876-9-173

Cite this article as: Butterfield et al:: Multiplex serum biomarker assessments: technical and biostatistical issues. Journal of Translational Medicine 2011 9:173.

\section{Submit your next manuscript to BioMed Central and take full advantage of:}

- Convenient online submission

- Thorough peer review

- No space constraints or color figure charges

- Immediate publication on acceptance

- Inclusion in PubMed, CAS, Scopus and Google Scholar

- Research which is freely available for redistribution

Submit your manuscript at www.biomedcentral.com/submit
C) Biomed Central 